\title{
Exploring the possibility of one-on-one mentoring as an alternative to the current student support system in medical education
}

\author{
Yera Hur, A Ra Cho ${ }^{2}$ and Sun Kim² \\ ${ }^{1}$ Institute of Medical Education, Hallym University College of Medicine, Chuncheon and ${ }^{2}$ Department of Medical \\ Education, College of Medicine, The Catholic University of Korea, Seoul, Korea
}

Purpose: The purpose of this study was to explore the possibility of mentoring as an alternative to the current student support system based on our experiences of developing, operating, and evaluating a mentoring program.

Methods: In 2014 and 2015, a total of 29 mentoring pairs were selected to be trained as mentors and mentees. The mentoring program was evaluated by the following methods. First, at the end of the one-on-one mentoring program, the mentee made a presentation summarizing their experiences and submitted a portfolio. Second, suggestions from the mentors and mentees were gathered from a survey and from a focus group interview. The quantitative data were analysed using descriptive statistics, frequency, and the Mann-Whitney U-test using SPSS version 21.0.

Results: One-on-one mentoring sessions were carried out an average of five times during the semester. The topics of discussion were very diverse, including career coaching, personal counselling, journal club, field trips, leisure activities, and volunteering. Mentors and mentees showed high satisfaction rates regarding the content and administration of the program (mentors: $4.15 \pm 0.59$, mentees: $4.00 \pm 1.58$ ). However, the duration of the mentoring program was given a comparatively low rating (mentors: $3.15 \pm 1.09$, mentees: $3.24 \pm 1.03)$.

Conclusion: Overall, the implementation of the mentoring program was successful. Based on the content of the main activities, we can confirm the possibility of implementing an individualized support program for solving the mentoring issues faced by medical students.

Key Words: Medical education, Medical students, Mentoring, Coaching, Counselling

\section{Introduction}

Medical students frequently face a significant amount of stress and anxiety due to a heavy academic workload in a competitive educational environment. Their emotional difficulties are comparable to those faced by emergency department interns [1]. To a greater extent than general university students, medical students must thoroughly master the material and undergo frequent examinations in a competitive and rigid educational climate and hierarchical organizational culture. A survey found that over $60 \%$ of students reported problems with their mental health [2]. The main problems faced by medical students are related to psychological and emotional issues, such as academic achievement, career development, interpersonal relationships, and depression [3-6]. To cope with these problems, medical schools
Received: February 6, 2018 • Revised: April 16, 2018 • Accepted: April 24, 2018 Corresponding Author: Sun Kim (https://orcid.org/0000-0002-5152-9153)

Department of Medical Education, College of Medicine, The Catholic University of Korea, 222 Banpo-daero, Seocho-gu, Seoul 06591, Korea

Tel: +82.2.2258.7200 email: skim@catholic.ac.kr
Korean J Med Educ 2018 Jun; 30(2): 119-130.

https://doi.org/10.3946/kjme.2018.87

eISSN: 2005-7288

(C) The Korean Society of Medical Education. All rights reserved. This is an open-access article distributed under the terms of the Creative Commons Attribution Non-Commercial License (http:// creativecommons.org/licenses/by-nc/3.0/), which permits unrestricted non-commercial use, distribution, and reproduction in any medium, provided the original work is properly cited. 
have implemented student support systems, generally in the form of an advisor system.

However, the content of the current student advisory system varies depending on the academic advisor, and the students are often dissatisfied with these programs, since they are often implemented as a formal one-time social meeting [7]. Many students who decide to take a leave of absence do not ask their supervisor for help, so they miss a chance to receive proper guidance and educational support [8]. This suggests that the current student advisory system offers limited practical guidance for continuous student support and does not offer effective responses based on a sufficient understanding of individual students. Thus, medical schools are attempting to develop and introduce mentoring programs. In a PubMed search with the keywords "(mentoring [Title/Abstract]) AND medical education [Title/ Abstract]", the first article on mentoring appeared in 1988. Through 2009, 69 papers were published, followed by a sharp increase, with 190 publications appearing from 2010 to 2017. This timeline suggests that mentoring in medical education is perceived as a new alternative to the existing student support system and is receiving wider interest. Mentoring is an integral part of the personal development and professional growth of medical students, helping them successfully grow as future physicians and researchers. It is also a key component of medical education and successful career development for medical students, and has achieved some meaningful and positive results [9-16]. In contrast, a search of KMbase using the formula "([TITLE= mentoring] OR [ABSTRACT=mentoring])", yielded only four articles as of August 2017 that addressed mentoring among medical students. Two of these articles reported actual experiences with mentoring, while one study dealt with mentoring hours using the existing student advisory system [17]. The other paper investigated small-group mentoring (academic study, research, etc.) with senior students [18]. Therefore, it is hard to find cases of mentoring being used as an alternative to the current academic advising or support system. With this background, the purpose of this study was to explore the possibility of mentoring as an alternative to the current student support system based on our experiences of developing, operating, and evaluating a mentoring program.

\section{Methods}

\section{Research subjects}

A total of 29 pairs participated in the one-on-one mentoring program piloted in 2014 and 2015 at the Catholic University of Korea College of Medicine (CUCM) and Konyang University College of Medicine (KUCM) (Table 1). This study included personal interviews and information about the activities of the participants, who were informed about the purpose of the study and were assured that participation was voluntary. Participants were also informed that if they did not wish the information to be used for research, they could

\begin{tabular}{lcccc}
\hline Table 1. Research Subjects & & & & \\
\hline \multicolumn{1}{c}{ Subject } & Year & No. of mentors & No. of mentees & Total \\
\hline College of Medicine, The Catholic University of Korea & 2015 & 7 & 7 & 14 \\
Konyang University College of Medicine & 2014 & 12 & 12 & 24 \\
& 2015 & 10 & 10 & 20 \\
Total & & 29 & 29 & 58 \\
\hline
\end{tabular}


withdraw it. Only data from participants who provided consent were used in the study. This study was approved by the Institutional Review Board of Songeui Medical Campus, the Catholic University of Korea (IRB approval no., MC16EIMI0025).

\section{Operating procedures of the mentoring program}

1) Selection of the mentoring type suitable for medical students

Mentoring programs are generally classified as formal and informal. They are also divided into one-on-one versus group mentoring, community-based versus schoolbased programs, and offline versus online mentoring [19]. Within this classification, the researchers selected formal, one-on-one mentoring to explore possibility of mentoring as an alternative to the current student advisory system.

Formal mentoring involves a systematic and planned match between mentors and mentees [20]. One-on-one mentoring is carried out through face-to-face meetings between mentors and mentees that involve conducting individualized activities such as personal counselling, leisure activities, and the provision of academic support. These traditional mentoring programs are appropriate for students who lack experience in a particular learning process or who are at a stage of conversion [21]. Therefore, the researchers chose formal one-on-one mentoring as an appropriate way to address the issues that have been pointed out in the current student advisory system. In addition, since medical students spend most of their time at school, the researchers determined that school-based mentoring, instead of community-based mentoring, would be more appropriate for medical schools. However, we allowed the mentoring pairs to freely choose between offline and online activities according to their preferences. Based on these considerations, we designed the medical school mentoring framework that is shown in Fig. 1.

2) Six stages of the one-on-one mentoring program The one-on-one mentoring program took place in six stages, including a mentor training course, one-on-one mentoring sessions, and finally a program evaluation session. As shown in Fig. 2, the first stage of the program involved planning and resource development. We developed the Start-Talking-Action-Transition (STAT) model for effective mentoring, a seven-step mentoring guide, and appropriate activity materials.

In the second stage, we recruited professors who wished to participate in the mentoring program by sending an email announcement to all faculty. In the third stage, we conducted training for mentors. The CUCM conducted a total of 12 hours of mentoring training (four workshops), and KUCM conducted a total of 13 hours of training (six workshops and one preparation session)

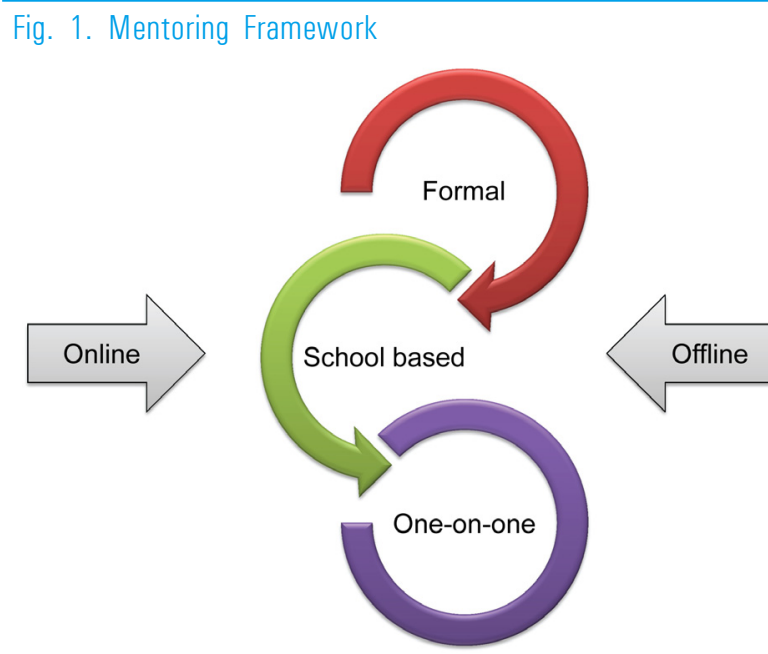

Fig. 2. Start-Talking-Action-Transition Model of Mentoring

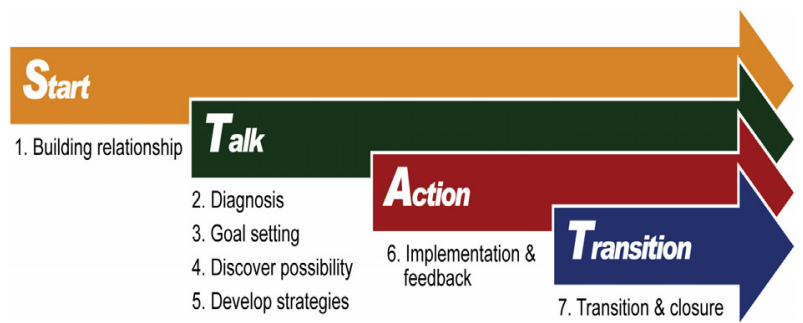


Fig. 3. Mentoring Training Process for Mentors

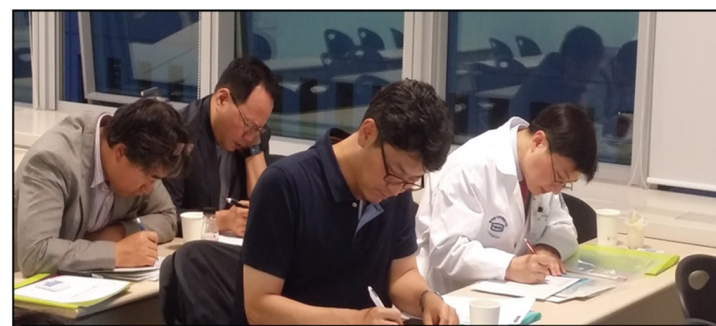

Understanding oneself and others: using personality inventories

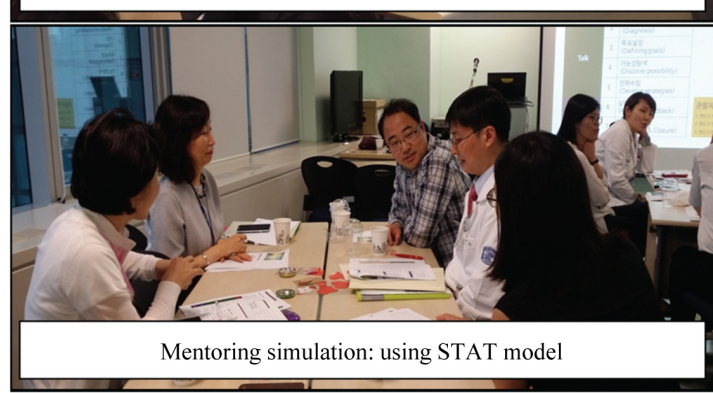

STAT: Start-Talking-Action-Transition.

(Fig. 3). Only professors who had completed all the training sessions were authorized to serve as mentors. In the fourth stage, mentors and mentees were matched as similar as possible equal gender. Students who wished to participate as mentees were recruited in two ways. The CUCM recruited applicants among first-year medical students (M1) who had been assigned to work with academic advisors who also had been appointed as mentors. The KUCM recruited volunteer mentees from the freshman year (PM1) who had the most time available for mentoring and then matched them with mentors through a comprehensive review of the personality test results of the mentors and mentees.

In the fifth stage, one-on-one mentoring was conducted for approximately 6 months, beginning with a mentor and mentee meeting where they signed a written pledge indicating that they understood the basic operating rules of mentoring. At least five meetings were recommended based on the STAT model of mentoring, but the specific goals and methods were determined by the mentor and the mentee, who operated independently as a pair. We did not offer mentors incentives or reimbursements for

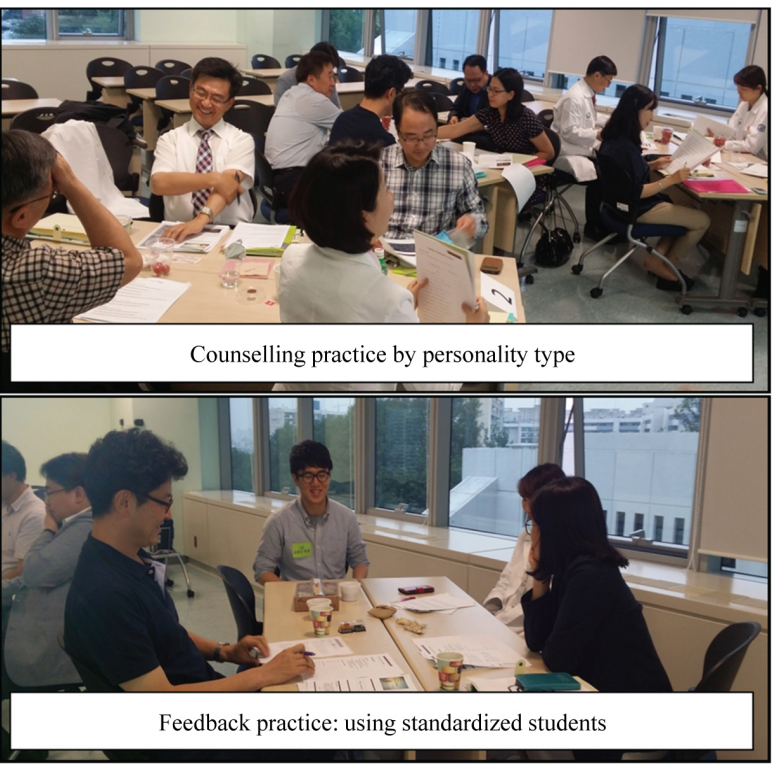

activity costs. The departments of medical education of both colleges, which were in charge of the program, provided relevant mentoring materials when requested by the mentor.

In the sixth stage, an evaluation session referred to as a "retreat" was held (Fig. 4). In the mentoring retreat, mentoring experiences were shared through mentor and mentee presentations and mutual evaluation. Finally, a focus group interview (FGI) and questionnaires were conducted to confirm the suitability and effectiveness of the one-on-one mentoring program. The questionnaire was developed by the researchers in advance and was completed through consultation with two medical education experts.

\section{Data collection and analysis}

The first step in data collection was gathering the details of the one-on-one mentoring program from the evaluation reports personated by the mentees during the retreat session, the mentors' logbooks, and the mentees' portfolios. The evaluation session lasted for approximately 1 hour and 30 minutes. There were a total of 53 
Fig. 4. Mentoring Evaluation Meeting

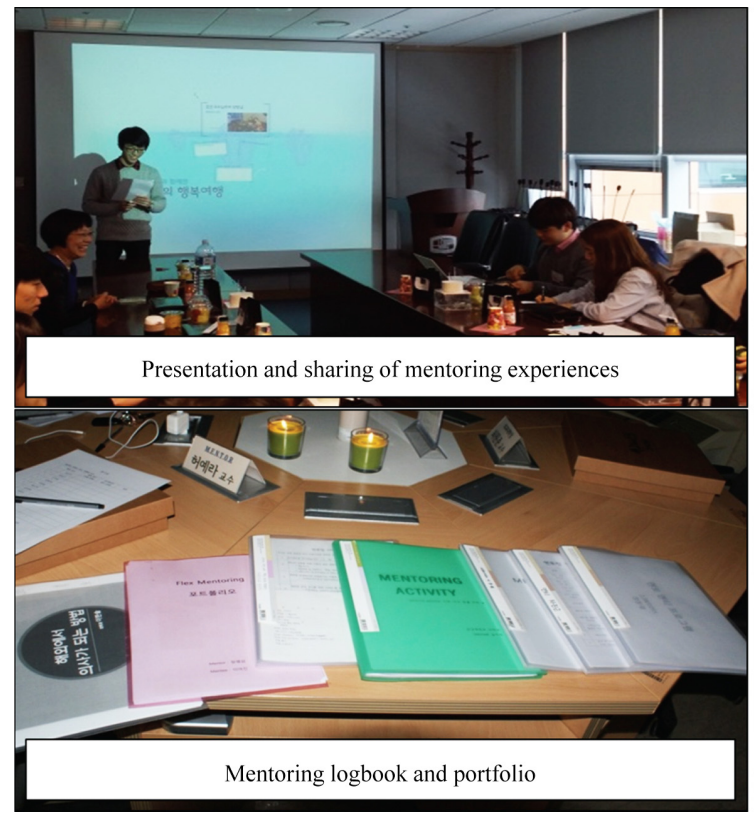

attendees, including nine CUCM participants (four mentors, five mentees), and 44 KUCM participants (12 pairs in 2014, 10 pairs in 2015).

Second, the mentors' and mentees' views on oneon-one mentoring programs were evaluated through a FGI and mentor and mentee questionnaires. The FGI was conducted during the evaluation session, and the questionnaire was administered to all participants in paper format and online. Excluding unanswered surveys, final responses were collected from 17 mentors and 20 mentees.

The details of the analysis of the data collected on one-on-one mentoring are as follows. The constituent elements of the portfolio, the mentoring logbook, and the presentations were gathered and categorized by meaning through the consensus of the researchers based on the purpose of the activity. All data were reviewed by two researchers to minimize the bias of the researcher or the reaction effect of the researcher. At this time, the main content was summarized verbally and in writing, and finally the responses of participants that were agreed to reflect similar content based on an analysis of

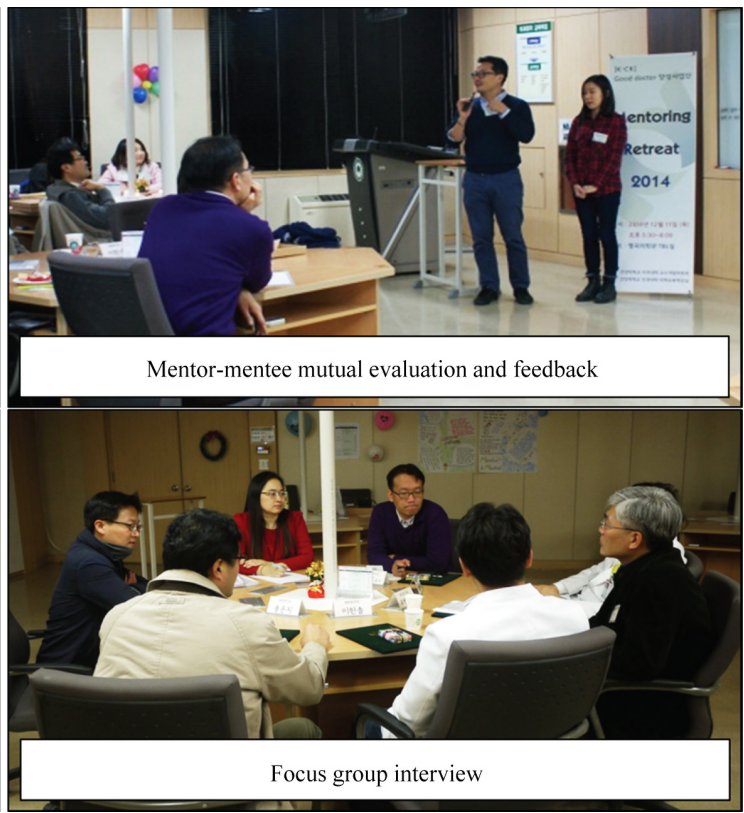

semantic units and to be representative were extracted and used. All data were reviewed by two researchers to minimize bias. In addition, participants in the FGI responded freely to the questions written by the researchers. In order to exclude the possibility of human rights violations and ethical concerns, the main content of the FGI was summarized to ensure that participants could not be identified. Responses of the participants that were agreed to be representative were extracted and used. Quantitative data were analysed with descriptive statistics, frequency analysis, multiple response analysis, and the Mann-Whitney U-test using IBM SPSS ver. 21.0 (IBM Corp., Armonk, USA).

\section{Results}

\section{Purpose of participating in the one-on-one mentoring program}

Mentors had the greatest expectations of broadening their educational experiences. Mentees' participation was 
determined by various factors such as academic support and general counselling about their career and personal life (Table 2).

\section{Results of the one-on-one mentoring program}

Table 3 shows the results of one-on-one mentoring for
5 to 6 months. Mentors and mentees had at least five meetings, with an average of 1 hour per meeting.

The specific activities of one-on-one mentoring differed across mentor-mentee pairs, but they can be distilled into three themes: formation of relationships, search and refinement of interests/career fields, and competency-building as future physicians. Table 4

Table 2. Purpose of Mentee and Mentee Participation

\begin{tabular}{clc}
\hline \multicolumn{1}{c}{ Subject } & \multicolumn{1}{c}{ Purpose of participation } & No. of response $(\%)^{a \mid}$ \\
\hline Mentor & Broadening educational experiences & $13(61.90)$ \\
& Developing a close student-faculty relationship & $7(33.33)$ \\
& Obtaining a higher score on a faculty performance evaluation & - \\
Mentee & Others & $1(4.76)$ \\
& Academic and school life support & $14(31.82)$ \\
& General consultation & $10(22.73)$ \\
& Meaningful and diverse experiences & $10(22.73)$ \\
& Creating a personal relationship with a professor & $8(18.18)$ \\
& Others & \\
\end{tabular}

${ }^{\text {al }}$ Multiple response analysis. ${ }^{b /} \mathrm{A}$ closed answers.

\begin{tabular}{llc}
\hline Table 3. Operational Details of One-on-One Mentoring & \\
\cline { 2 - 3 } \multicolumn{1}{c}{ Classification } & \multicolumn{1}{c}{ Category } & No. of response (\%) $)^{\text {al }}$ \\
\hline No. of meetings & Fewer than 1 to 3 times & $2(5.71)$ \\
& From 3 to 5 times & $11(31.43)$ \\
& More than 5 times & $22(62.86)$ \\
Average meeting hours & Less than 1 hour & $16(47.06)$ \\
& More than 1 hour & $18(52.94)$ \\
Mentoring location ${ }^{\text {a) }}$ & Professors' office, doctor's office & $24(46.15)$ \\
& Restaurant, cafeteria & $16(30.77)$ \\
& Others $^{\text {b) }}$ & $12(23.08)$ \\
\hline
\end{tabular}

${ }^{a}$ Multiple response analysis. ${ }^{\text {bl}}$ Hospital, laboratory, theatre, park, exposition ground, welfare institution, etc.

Table 4. One-on-One Mentoring Content by Category

\begin{tabular}{|c|c|c|c|}
\hline Period & Category & Activity & Aim \\
\hline \multirow[t]{5}{*}{$\begin{array}{l}\text { First } \\
\text { meeting }\end{array}$} & $\begin{array}{c}\text { Information } \\
\text { gathering }\end{array}$ & $\begin{array}{l}\text { Psychological tests: FIRO-B, GPA, MBTI, } \\
\text { NEO ॥ }\end{array}$ & $\begin{array}{l}\text { Understanding of oneself } \\
\text { Gathering basic information about the mentee }\end{array}$ \\
\hline & & Checklist for the mentee & $\begin{array}{l}\text { Confirming the current circumstances of the mentee (school life, } \\
\text { academic performance, interpersonal relationship, emotional } \\
\text { issues, etc.) }\end{array}$ \\
\hline & $\begin{array}{l}\text { Rapport } \\
\text { building }\end{array}$ & Introducing oneself, sketching out a life curve & Mutual understanding \\
\hline & Agreement & Mentoring pledge & Agreement on mentoring methodsand principles \\
\hline & & Mentoring schedule & $\begin{array}{l}\text { Setting long-term and short-term goals } \\
\text { Determination of performance evaluation criteria and methods }\end{array}$ \\
\hline
\end{tabular}

(Continued to the next page) 


\begin{tabular}{|c|c|c|c|}
\hline Period & Category & Activity & Aim \\
\hline \multirow[t]{4}{*}{$\begin{array}{l}\text { After first } \\
\text { meeting }\end{array}$} & Counselling & $\begin{array}{l}\text { General consulting and medical school life } \\
\text { roadmap } \\
\text { Vision statement and to-do checklist } \\
\text { Happy tree and compliment shower }\end{array}$ & $\begin{array}{l}\text { Support adaptation to college, resolve psychological difficulties, } \\
\text { etc. } \\
\text { Exploring possibilities and setting goals } \\
\text { Strategy formulation and practice } \\
\text { Improve self-esteem }\end{array}$ \\
\hline & Recreation & $\begin{array}{l}\text { Watching movies, hiking, bicycling, and } \\
\text { reading } \\
\text { Gardening, volunteering activities (knitting } \\
\text { hats, etc.) }\end{array}$ & $\begin{array}{l}\text { Maintaining a reliable relationship } \\
\text { Understanding positive life attitudes } \\
\text { Enhancing interpersonal skills }\end{array}$ \\
\hline & $\begin{array}{l}\text { Academic } \\
\text { study }\end{array}$ & $\begin{array}{l}\text { Journal club, study club } \\
\text { Connecting with a professor with a similar } \\
\text { field of interest } \\
\text { Talent donation (translating movie subtitles } \\
\text { etc.) }\end{array}$ & $\begin{array}{l}\text { Opportunities for deepening and further development of interest } \\
\text { areas } \\
\text { Enhancement of competency as a doctor }\end{array}$ \\
\hline & $\begin{array}{l}\text { Career } \\
\text { coaching }\end{array}$ & $\begin{array}{l}\text { Career planning } \\
\text { Hospital field trip lexamining test results etc.) } \\
\text { Unit meeting attendance }\end{array}$ & $\begin{array}{l}\text { Specification of career planning, establishing a strategy } \\
\text { Work experience of a doctor } \\
\text { Development and refinement of career goals as a doctor }\end{array}$ \\
\hline Final & Evaluation & $\begin{array}{l}\text { Final evaluation sheet } \\
\text { Writing a letter to myself in the future }\end{array}$ & $\begin{array}{l}\text { Checking changes and mentoring achievement } \\
\text { Mentoring self-assessment and feedback } \\
\text { Deciding to maintain or end a mentee relationship with a mentor } \\
\text { Self-reflection }\end{array}$ \\
\hline
\end{tabular}

FIRO-B: Fundamental Interpersonal Relations Orientation-Behaviour, GPA: Korean version of the Geometry Psychology, MBTI: Myer-Briggs Type Indicator, NEO II: Neuroticism Extraversion Openness to experience II.

Table 5. Satisfaction with the One-on-One Mentoring Program

\begin{tabular}{lcccc}
\hline \multicolumn{1}{c}{ Survey item } & Mentor & Mentee & $\begin{array}{c}\text { Mann-Whitney } \\
\text { U statistics }\end{array}$ & p-value \\
\hline Was the mentoring period appropriate? & $3.15 \pm 1.09$ & $3.24 \pm 1.03$ & 166.00 & 0.916 \\
Was the mentor's/mentee's attitude satisfactory? & $4.55 \pm .051$ & $4.41 \pm 0.51$ & 146.50 & 0.478 \\
$\begin{array}{l}\text { Were the content and implementation of mentoring } \\
\text { satisfactory? }\end{array}$ & $4.15 \pm 0.59$ & $4.00 \pm 1.58$ & 140.50 & 0.373 \\
$\begin{array}{l}\text { Question for mentee: Did you receive on-time and accurate } \\
\text { feedback? }\end{array}$ & - & $4.40 \pm 0.59$ & - & - \\
$\begin{array}{l}\text { Question for mentor: Did you feelthat this process was } \\
\text { rewarding to you as a professor? }\end{array}$ & $4.59 \pm 0.51$ & - & - & - \\
\hline
\end{tabular}

Data are presented as mean \pm standard deviation of 5-point Likert scales.

summarizes the activities and objectives from specific time periods collected through the mentors' logbooks and the mentees' portfolios.

\section{Evaluation of the one-on-one mentoring program}

The scores for mentoring program satisfaction were generally 4 points or more, and the Mann-Whitney U-test showed no significant differences between the mentors and mentees. However, neither group was satisfied with the duration of the mentoring program (Table 5).

Specifically, they stated that the mentoring program was too short, suggesting that a minimum of 6 months or 1 to 2 years should be required. In addition, some participants expressed the opinion that the mentormentee relationship should be maintained from the time of entrance until graduation. 
We asked mentors and mentees to freely answer three questions in order to gather specific comments on one-on-one mentoring programs. First, when asked, "What difficulties did you experience in meeting with the mentor/mentee?" the most frequent response from mentees was that it was difficult to make appointments with the mentors due to their busy schedule. Additionally, some mentees felt that it was difficult to open themselves up to mentors. Mentees described the following difficulties in detail:

"My mentor who was a physician was very busy, so it was hard to schedule our mentoring time, and when we met, the time was too short." (PM1, KUCM)

"I was worried about how much I had to expose my personal stories and my secrets." (M1, CUCM)

The same question was asked to the mentors, and the mentors replied that they had the following difficulties:

"It was difficult to have regular mentoring meetings due to emergency surgery, staff meetings, and hospital duties." (Professor, KUCM)

"It was difficult for me to deliver proper mentoring because the mentee found it difficult to open up his/her mind and heart." (Professor, CUCM)

For the question "What was the best thing about the mentoring program?", the mentees responded as follows:

"It was good to have a chance for one-on-one meetings with a professor. It is very rare for me to come across a person who looks after me on an ongoing basis, especially as a one-on-one mentor." (PM1, KUCM) "I am pleased that I can plan my future path based on field trips to the hospital and a variety of activities with my mentor." (M1, CUCM)
To the same question, the mentors responded:

"It was nice to talk deeply and develop a special relationship with a student and to be capable of giving sincere advice. This is hard to do when you meet a student in formal classes." (Professor, CUCM)

"As a mentor, I had the opportunity to understand my shortcomings as a professor and found the chance to improve myself. I also felt proud as a professor." (Professor, KUCM)

Finally, to the question "What part of the mentoring program needs to be supplemented?" the mentees responded as follows:

"Mentoring was too short for me. ${ }^{\cdots}$ So I guess 1 semester for mentoring is not enough." (PM1, KUCM) "I wish there was sufficient guidance about mentoring in advance. In addition, the department should monitor whether the mentoring is running well." (M1, CUCM)

Mentors, in contrast, emphasised the need for university support, and one mentor suggested the need to further discuss the timing and methods of delivering the results of the mentees' psychological tests. Some specific opinions included:

"It is likely that giving the mentee's information to the mentor in advance may result in prejudice. I think it would be better if the mentor first establishes rapport with the mentee and then is provided the relevant information about the mentee upon request." (Professor, CUCM)

"I think the university should support the cost of mentoring activities and secure dedicated time for mentoring." (Professor, KUCM) 


\section{Discussion}

There has been a rapid increase in discussions about mentoring since 2010, and mentoring programs have been actively applied in basic medical education, postgraduate medical education, and clerkships. As such, the scope of mentoring has been diversified to include residents, professors, and physicians as well as medical students, thus disproving the idea that mentoring can only play a positive role in medical education. In addition, the Korea Institute of Medical Education and Evaluation, which sets accreditation standards for medical schools, has suggested that one of the accreditation standards should include guidance for students in their academic studies and school life, as well as appropriate career guidance systems, such as mentoring programs and mentor training programs. In this context, medical schools have realised the importance of developing and operating one-on-one mentoring programs as a systematic and practical student support system.

This study sought to explore the possibilities of one-on-one mentoring programs as an alternative to current student support systems based on our experiences of a one-on-one mentoring program for medical students, and to identify effective strategies for implementing such programs. The results of this study have the following implications. First, the mentors and mentees who participated in the one-on-one mentoring program had an average of 1 to 5 hours of meetings for roughly 6 months (1 semester), and both groups showed high satisfaction with respect to the mentoring hours. In particular, we concluded that it was possible to provide in-depth counselling and appropriate support through a special mentoring relationship. Specifically, mentors and mentees reported that they experienced in-depth counselling and appropriate support through their individualized relationship with each other. This was because the one-on-one mentoring structure overcame the limitations of the current student support system, making it a viable alternative. Additionally, mentoring was conducted mainly at schools, in professors' offices or clinical settings. Our findings suggest that a school-based one-on-one mentoring structure is appropriate for medical schools. In particular, our analysis of major mentoring activities showed that the mentoring content included counselling about academic support, refining career goals, solving personal anxiety, and overcoming psychological difficulties. This suggests that one-on-one mentoring can serve as an individualized support program to address the mentoring issues experienced by medical students. The positive results were not limited to mentees. The mentors also assessed mentoring as a meaningful educational experience and as an opportunity to understand and complement their shortcomings as professors. However, for a formal systematic mentoring system to be developed and operated, the following points should be considered.

First, a sufficient one-on-one mentoring period must be ensured. The participants suggested that a period of 1 to 2 years would be adequate. Considering the special circumstances of medical schools and teaching hospitals, it is often difficult to have long mentoring meetings, so an optimal mentoring program would last for more than a year, providing the ability to hold regular but relatively short meetings.

Second, mentees found it difficult to open themselves up to their mentors. They did not know how much they should disclose about personal matters to their mentors, and the mentors experienced difficulties in building a close relationship with the mentees because the mentees did not freely disclose their issues to the mentors. This may have been because medical students inherently tend 
to keep matters confidential and are often noncompliant when counselled [22]. Therefore, the mentoring department needs to provide various methods to support rapport formation and the maintenance of a trusting relationship.

Third, not providing the results of the mentee's psychology and personality test to the mentor in advance should be considered as way of preventing any prejudice that could hinder the formation of a desirable mentormentee relationship. Therefore, even if the mentee consents, the timing and method of delivery should be carefully reviewed. One possibility would be to provide information only upon the request of the mentor.

Fourth, we need to provide a support system for medical schools and hospitals. All the mentors expressed difficulty in securing time for mentoring because of their patient care obligations and assigned activities as medical professors. For a one-on-one mentoring program to function as an official student support system, appropriate time and budgetary resources should be provided. In this study, no mentors participated in the program in order to improve their scores on faculty performance evaluations, but incentives need to be considered. It is also important to note that overseas schools, which have already actively adopted one-on-one mentoring, continue to discuss institutional compensation systems and financial support for mentors [23-25].

Fifth, the program should be operated systematically with support from a responsible department or team. In this study, one-on-one mentoring was conducted with mentors and mentees functioning autonomously. However, even though both mentors and mentees should have autonomy in the details of mentoring activities, core thematic guidelines should be provided. Periodic review and adjustment of the progress of one-on-one mentoring and appropriate monitoring should be provided. A suggestion was made to establish a responsible depart- ment or a team, which would develop concrete guidelines for mentoring topics such as counselling, academic learning, and career coaching, and would play a practical role in providing relevant activities and resources in accordance with the needs of the mentors and mentees.

Finally, efforts are needed to ensure a sufficient number of mentors and to manage the quality of mentors. Many studies have emphasized that continuing instruction and mentoring guidance should be provided because the mentor's competency is a key component of successful mentoring [16,26-28]. Therefore, follow-up studies should attempt to characterize the qualities of mentors and continually enhance their mentoring skills.

Based on our experience with a mentoring program for medical students, we propose the possibility of oneon-one mentoring as an alternative to the current student advisory system. In addition, short-term training enables mentors to acquire and apply the core mentoring skills needed, facilitates the mentor's growth, and encourages the development of positive relationships with mentees.

Although this study was limited to two of the 40 medical schools in Korea, it confirmed the possibility and significance of a one-on-one mentoring program in medical education. Based on this research, individual medical schools will be able to develop and operate various forms of mentoring that reflect the needs of the students and professors of their institution. In particular, we hope that students will develop a more healthy and balanced life in medical school through specialized forms of mentoring, such as academic mentoring, career mentoring, and personal mentoring, by building upon the scope of the one-on-one mentoring analysed in this study. 


\section{ORCID:}

Yera Hur: https://orcid.org/0000-0002-0142-3078;

A Ra Cho: https://orcid.org/0000-0003-0458-5256;

Sun Kim: https://orcid.org/0000-0002-5152-9153

Acknowledgements: None.

Funding: The authors wish to acknowledge the financial support of the Catholic Medical Center Research Foundation made in the program year of 2016.

Conflicts of interest: No potential conflict of interest relevant to this article was reported.

Author contributions: Conception and design of the work: YH, ARC, SK; data collection: YH, ARC; data analysis and interpretation: ARC; drafting the article: ARC; critical revision of the article: YH, ARC; and final approval of the version to be published: YH, ARC, SK.

\section{References}

1. Hur Y, Cho AR, Kim S. Operation of a school adaptation program considering the interpersonal needs of medical freshmen. Korean J Med Educ. 2014;26(4):283-289.

2. Korea Association of Medical Colleges. Survey of mental health of medical school students in Korea. http:// kamc.kr/data/bbs/b74054_\%EC\%A0\%84\%EA\%B5\%AD_ \%EC\%9D\%98\%EA\%B3\%BC\%EB\%8C\%80\%ED\%95\%9 9\%EC\%83\%9D_\%EC\%A0\%95\%EC\%8B\%A0\%ЕA\%B। \%В4\%ЕА\%B0\%95_\%ЕС\%8B\%A4\%ED\%83\%9C\%ЕС\% Al\%B0\%EC\%82\%AC_\%EC\%B5\%9C\%EC\%A2\%85(200 7).pdf. Published March 2007. Accessed December 27, 2017.

3. Kim NC, Kim SH, Lhm HK, et al. Comparison of stress and life satisfaction between non-medical and medical college students. Korean J Psychosom Med. 2015;23(1): 47-56.

4. Kim MS, Kim JH, Kim DY, Kim JH, Park HJ. Awareness of students for implementation of a peer mentoring program in a medical school. Keimyung Med J. 2016; 35(2):113-121.

5. Min SK, Shin WC, Kim KI, Chung JI, Kim DK. Comparison of quality of life between medical students and general college students. J Korean Neuropsychiatr Assoc. 2000;39(6):1054-1060.

6. Han SS, Lee SY, Choi WS, Kim SJ, Park SB, Lee SY. Depression and its influencing factors among Korean medical and engineering students in urban areas using Zung Self-Rating Depression Scale. Korean J Fam Med. 2009;30(7):539-548.

7. Hur Y, Lee K. Are medical students being properly cared for?: a question for the current student advisory program. Korean J Med Educ. 2013;25(3):221-228.

8. Han ER, Chung EK, Oh SA, Chay KO, Woo YJ. Medical students' failure experiences and their related factors. Korean J Med Educ. 2012;24(3):233-240.

9. Frei E, Stamm M, Buddeberg-Fischer B. Mentoring programs for medical students: a review of the PubMed literature 2000-2008. BMC Med Educ. 2010;10:32.

10. Aba Alkhail B. Near-peer-assisted learning (NPAL) in undergraduate medical students and their perception of having medical interns as their near peer teacher. Med Teach. 2015;37 Suppl 1:S33-S39.

11. Castillo J, Goldenhar LM, Baker RC, Kahn RS, Dewitt TG. Reflective practice and competencies in global health training: lesson for serving diverse patient populations. J Grad Med Educ. 2010;2(3):449-455.

12. Kalén S, Ponzer S, Silén C. The core of mentorship: medical students' experiences of one-to-one mentoring in a clinical environment. Adv Health Sci Educ Theory Pract. 2012;17(3):389-401.

13. Lindström UH, Hamberg K, Johansson EE. Medical students' experiences of shame in professional enculturation. Med Educ. 201 1;45(10):1016-1024.

14. O'Sullivan PS, Niehaus B, Lockspeiser TM, Irby DM. 
Becoming an academic doctor: perceptions of scholarly careers. Med Educ. 2009;43(4):335-341.

15. Rehman R, Usmani A, Omaeer Q, Gul H. "Mentorship" a stride towards maintenance of medical student's well being. J Pak Med Assoc. 2014;64(12):1352-1357.

16. Yarris LM, Coates WC. Creating educational leaders: experiences with two education fellowships in emergency medicine. Acad Emerg Med. 2012;19(12):1481-1485.

17. Kim J, Lee K, Hwang WM, Kang J. How to get students actively involved in course development: an experience in developing and implementing a mentoring program for medical students. Korean J Med Educ. 2013;25(2): 157-165.

18. Kim J, Lee SH, Kim EJ, Kim H, Hwang J. A case study on small group teaching programs in medical school: SNU mentoring, peer tutoring, coaching, and research mentoring programs. Korean Med Educ Rev. 2012;14(2): 78-85.

19. Korea Youth Counselling and Welfare Institute. Mentoring program for obesity prevention of youth. http://www.kyci.or.kr/fileup/lib_pdf/1999-16.pdf. Published December 1999. Accessed December 27, 2017.

20. Jang DH, Kim JE. Study of college student experience success mentoring activities. J Inst Soc Sci. 2016;27(2): 215-235.

21. Kim JC, Sung KJ. Survey and discussion to stimulate mentoring program activities for college students. J Educ Res. 2009;16:97-118.

22. Kim KH, Kwon KI, Jang JH, Shin M. A qualitative study on counseling experience with medical student. Korean J Couns. 2015;16(5):1-21.

23. Fornari A, Murray TS, Menzin AW, et al. Mentoring program design and implementation in new medical schools. Med Educ Online. 2014;19:24570.

24. Nakanjako D, Byakika-Kibwika P, Kintu K, et al. Mentorship needs at academic institutions in resourcelimited settings: a survey at Makerere University College of Health Sciences. BMC Med Educ. 2011;11:53.

25. Singh S, Singh N, Dhaliwal U. Near-peer mentoring to complement faculty mentoring of first-year medical students in India. J Educ Eval Health Prof. 2014;11:12.

26. Caruso TJ, Steinberg DH, Piro N, et al. A strategic approach to implementation of medical mentorship programs. J Grad Med Educ. 2016;8(1):68-73.

27. Guse J, Schweigert E, Kulms G, Heinen I, Martens C, Guse AH. Effects of mentoring speed dating as an innovative matching tool in undergraduate medical education: a mixed methods study. PLoS One. 2016; II(2):e0147444.

28. Overeem K, Wollersheimh HC, Arah OA, Cruijsberg JK, Grol RP, Lombarts KM. Factors predicting doctors' reporting of performance change in response to multisource feedback. BMC Med Educ. 2012;12:52. 